\title{
Erratum to: Atomic Layer Deposition (ALD) as a coating tool for reinforcing fibers
}

\author{
A. K. Roy • W. Baumann • I. König • G. Baumann • \\ S. Schulze • M. Hietschold • T. Mäder • D. J. Nestler • \\ B. Wielage $\cdot$ W. A. Goedel
}

Published online: 13 July 2011

(C) Springer-Verlag 2011

Unfortunately, there was a mistake in figure 6 of the original article. The thermogravimetric analysis of the uncoated fibres was assigned to the wrong time scale and this gave rise to incorrect assignments of oxidation temperatures. The correct diagram is as follows:

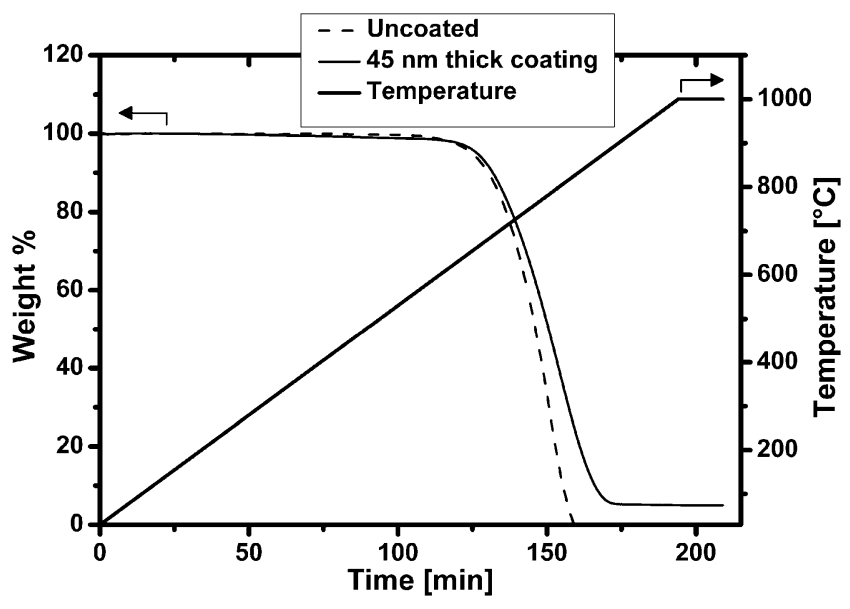

The online version of the original article can be found at http://dx.doi. org/10.1007/s00216-010-3470-9.

\footnotetext{
A. K. Roy · W. Baumann • I. König · W. A. Goedel $(\bowtie)$

Physical Chemistry, Institute of Chemistry,

Chemnitz University of Technology,

Strasse der Nationen 62,

09111 Chemnitz, Germany

e-mail: werner.goedel@chemie.tu-chemnitz.de

G. Baumann $\cdot$ S. Schulze $\cdot$ M. Hietschold

Solid Surfaces Analysis Group, Institute of Physics,

Chemnitz University of Technology,

Reichenhainer Strasse 70,

09126 Chemnitz, Germany

T. Mäder • D. J. Nestler $\cdot$ B. Wielage

Institute of Material Science and Engineering,

Chemnitz University of Technology,

Erfenschlager Strasse 73,

09125 Chemnitz, Germany
}

Taking the corrected diagram into account, the corresponding statements in the text need to be corrected as well:

- page 1917 right column first paragraph:

The results are shown in Fig. 6; oxidation onset temperature for the uncoated fibre as well the coated fibre is approximately $630{ }^{\circ} \mathrm{C}$. The uncoated fibres are completely burned at a temperature of approximately $825^{\circ} \mathrm{C}$, while the fibres coated with $45 \mathrm{~nm}$ of alumina are completely burned at temperatures of approximately $880{ }^{\circ} \mathrm{C}$. Thus, there might be a moderate oxidation protection of the fibres by the alumina coating.

- page 1917 right column last paragraph:

Our main objective was to show that ALD with non oxidative precursors can be used to coat carbon fibres with little or no damage and that the resulting coating may serve as an oxidation barrier. We conclude that ALD, which is already used in the semiconductor industry, is also a promising tool to coat reinforcing fibres that may be used in composites. 